\title{
A shape modification of the balancing slot of the impulse turbine stage with the drum rotor arrangement
}

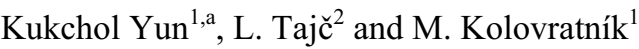 \\ ${ }^{1}$ Czech Technical University in Prague, Department of Mechanical Engineering, Technická 4 Praha 6, Czech Republic \\ ${ }^{2}$ University of West Bohemia, Department of Mechanical Engineering, Univerzitní 22 Plzeň, Czech Republic
}

\begin{abstract}
At the previous conference in Český Krumlov it was presented how the balancing slots may influence the efficiency of the impulse turbine stage with the drum rotor arrangement. A few options for shape modification of the balancing slot were also suggested. Implementation of the balancing slots and their possible modifications are subject to various design and technological limitations. During the consultation with the turbine designers and technologists, we were able to determine the modification of the balancing slot which, in terms of their design and production technology, will be the most simple and feasible. It is predicted that the suggested shape modification of the balancing slot will improve the efficiency of the turbine stage. This prediction is then supported by CFD simulations.
\end{abstract}

\section{Introduction}

The drum rotor arrangement in the impulse turbine is one of the original concepts of Doosan Škoda Power Company for the construction of industrial steam turbines. This new concept enables the low-output turbines to extend the rotor blades and in this way lowers their boundary losses.

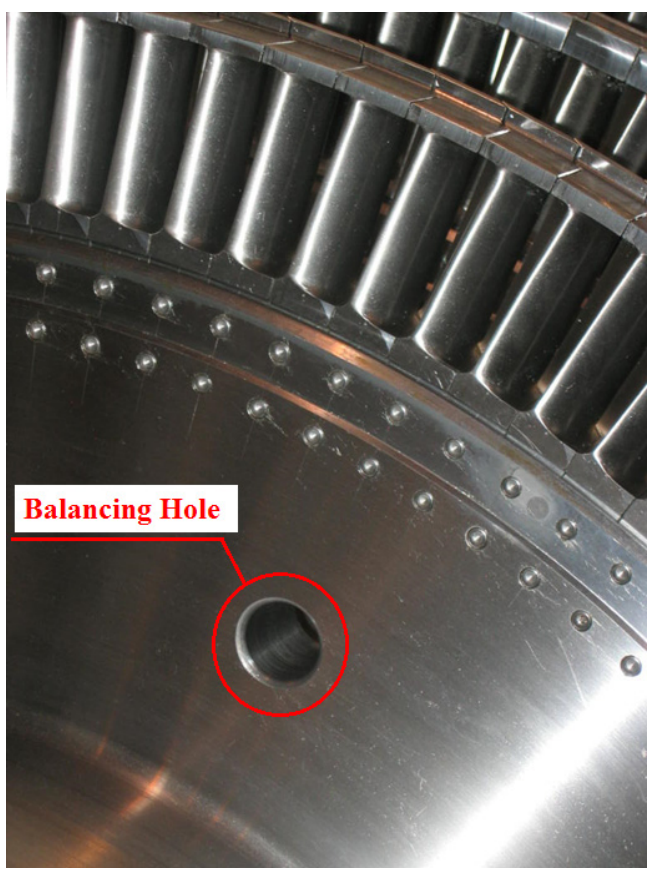

Figure 1. A balancing hole of an impulse turbine stage with classic rotor arrangement

${ }^{\mathrm{a}}$ Kukchol Yun: kukchol.yun@gmail.com
As is well-known, rotor blades of a classical impulse turbine stage are fitted into a large rotor disc, where sizeable balancing holes are placed (see figure. 1). These balancing holes primarily serve to balance pressures in front of and behind the rotor. Because of this, the axial force affecting the disc decreases. The pressure balancing in front of and behind the rotor disc is accomplished by extracting the seal steam by properly dimensioned balancing slots. Unlike in a traditional rotor arrangement of an impulse turbine, the blades in the drum rotor arrangement are placed directly on the drum rotor without using the rotor disc. This constructional design does not allow the application of the balancing holes in the way used in the traditional impulse turbine stage. In other words, the seal steam in a turbine stage with the drum rotor arrangement cannot be extracted by the balancing holes.

In the new concept, there are two possibilities how to transfer the seal steam behind the turbine stage.

The first possibility is to have all the seal steam blown into the gap between the stator (nozzle) blades and rotor (bucket) blades. In this case a fusion of the main steam (steam coming from the nozzle blade cascades) and the seal steam occurs. The seal steam has a velocity and flow direction that differs from that of the main steam. Its temperature is also higher than that of the main steam. Their mixing causes a change in aerodynamic and thermodynamic parameters in front of the rotor blades, specifically near their hub area. The influence of this change in these parameters on the efficiency of the corresponding turbine stage is described in detail in our 
paper from the previous conference [1]. It can be stated with certainty that the blowing of the seal steam always causes a decrease in the efficiency of the impulse turbine stage.

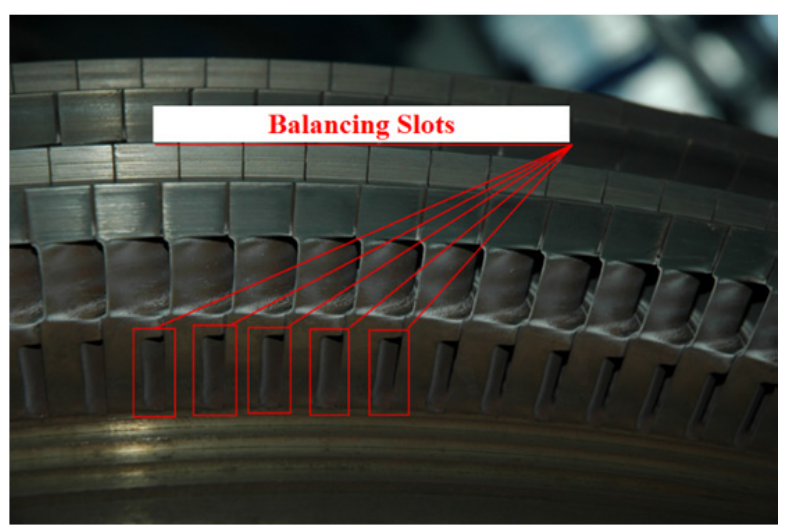

Figure 2. Balancing slots of an impulse turbine stage with the drum rotor arrangement

Another possibility how to solve the problem with seal steam in the drum rotor arrangement is to find an alternative for the classical balancing holes. Specifically, in our case the balancing holes are replaced by slots with small cross-section areas, which are a part of every rotor blade. These slots are called balancing slots (see figure 2). The results of numerical calculations clearly show that the extracting of the seal steam through the balancing slots has a positive influence on aerodynamic and thermodynamic parameters of the steam flow upstream from the rotor blades, and in this way leads to an increase in the efficiency of the turbine stage (see figure 3).

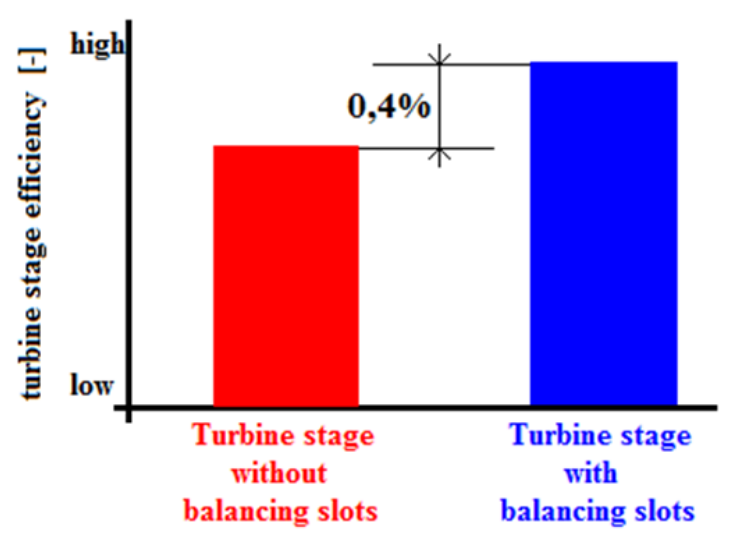

Figure 3. Comparison of the efficiencies of the turbine stage with and without balancing slots

\section{Balancing Slots and Their Shape Modification}

As mentioned above, in an impulse turbine with the drum rotor arrangement, it is necessary to implement the balancing slots for an improvement in efficiency.

These balancing slots are essentially replacements for the balancing holes of a classical impulse turbine stage. Thus these slots must meet all the requirements that are typical for the balancing holes. In addition, they have to satisfy another specific requirement which is derived from the constructional particularity of the new drum concept.

The balancing slots in the drum rotor arrangement are placed nearer to the shaft seal than the balancing holes in the traditional rotor arrangement (see figure 4).
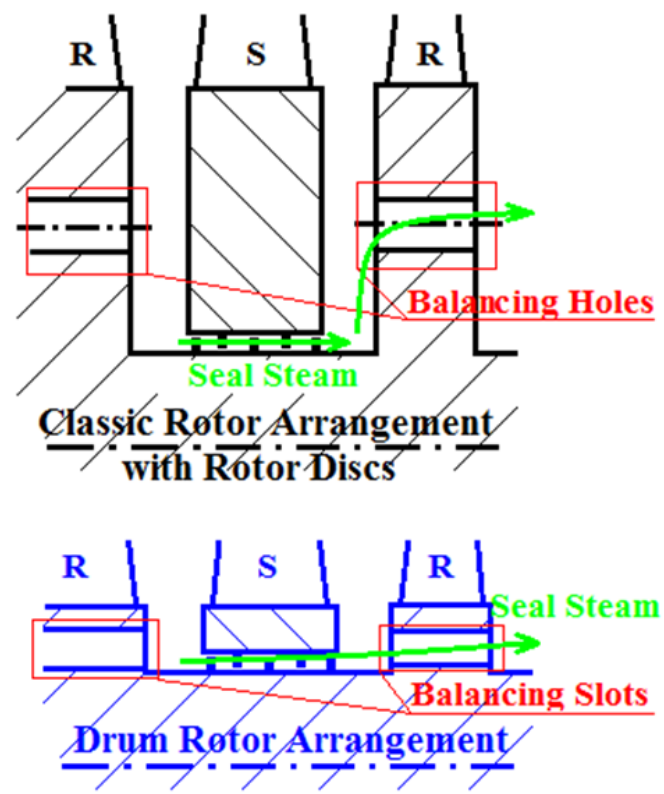

Figure 4. Balancing slots of an impulse turbine stage with the drum rotor arrangement

Thanks to this arrangement, the seal steam moves immediately to the balancing slots and thus its kinetic energy is not "wasted". Because of this, it is possible to get greater output from the seal steam flow through the balancing slots (The balancing slots could have mechanical output).

The amount of output gained in this way will depend on the ability of the balancing slots to effectively use the kinetic energy of the seal steam. For this reason, to maximize the utilisation of the kinetic energy of the seal steam is another requirement, which the balancing slots have to satisfy.

When the steam flows along the turbine blade profile, different pressures occur on its pressure and suction side. The pressure on the pressure side is generally higher than the pressure on the suction side. The output of the steam flowing through the blade cascade corresponds to this pressure gradient.

Similarly, the seal steam flow through the balancing slots will produce output if the pressure on the pressure side of every balancing slot is higher than the pressure on its suction side.

In the opposite case, the seal steam flow will produce "negative" output, i.e. it will slow down the rotor.

To depict clearly the pressures on both sides of the balancing slot, a few control lines have been created (see figure 5).

The pressures on these lines are shown in figure 6 . 


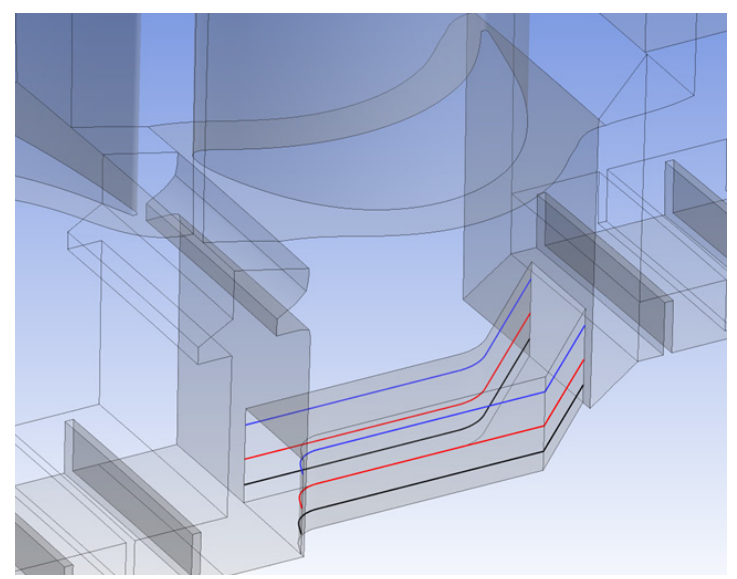

Figure 5. Control lines created on the side walls of the balancing slot

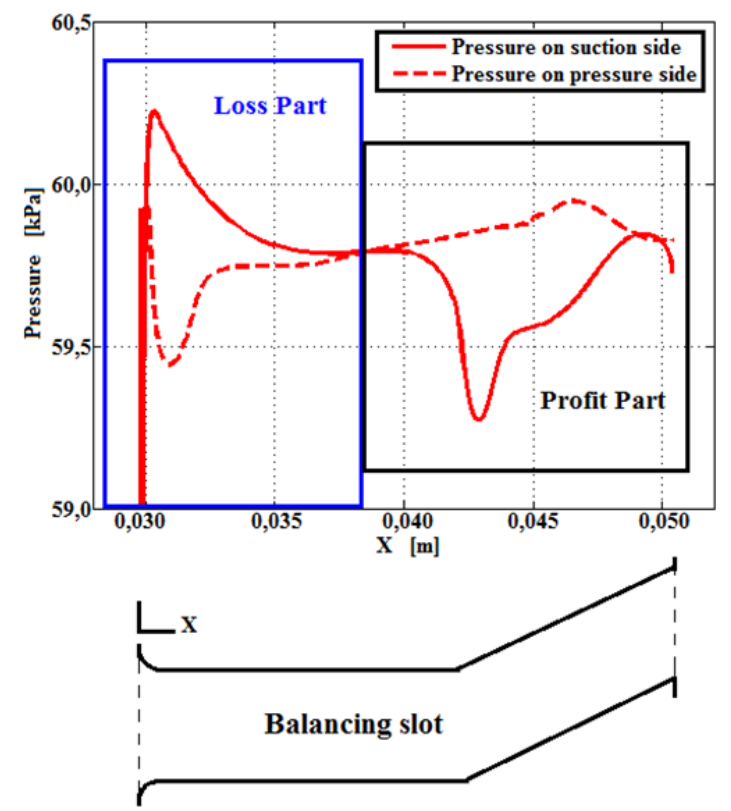

Figure 6. Pressure distribution on the control lines

The production of output in the balancing slot can be divided into two parts - the profit and the loss. It is obvious that the amount of output produced by the steam flow through the balancing slot depends on its profit and loss part ratio. Specifically, the larger the profit part of the balancing slot, the higher its mechanical output and vice versa. As described in our paper from the previous conference [1], an expansion of the profit part of the balancing slot can be reached by a change in the outlet angle of the seal steam flow and by acceleration of the steam flow at its outlet. In both cases a reduction in the tangential velocity of the steam flow on the balancing slot outlet occurs and it leads to an increase in the mechanical output of the balancing slot (see figure 7).

As mentioned before, the balancing slot is a part of each rotor blade. For this reason, its shape modification certainly leads to a geometric change of the rotor blade. To change a blade's geometry is very complicated both in terms of construction and technology. It is also very expensive.

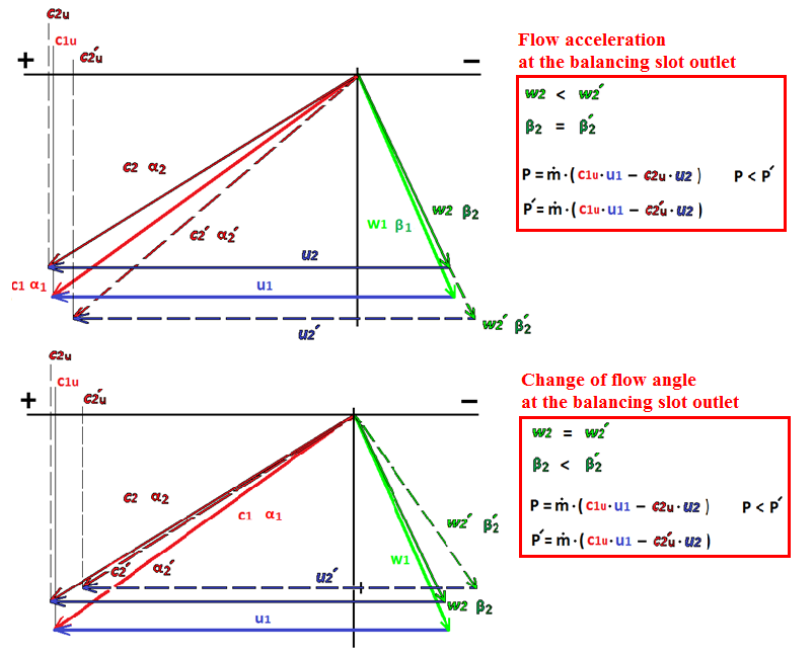

Figure 7. Steam flow acceleration and change of flow angle at the balancing slots outlet

That's why we tried to discover a shape modification of the balancing slot, which causes minimal interference with the rotor blade while at the same time enabling the change in the outlet angle and acceleration of the steam flow at its outlet.

One of the modifications which meets the above mentioned criteria is gradual narrowing of the balancing slot's outlet channel (see figure 8).

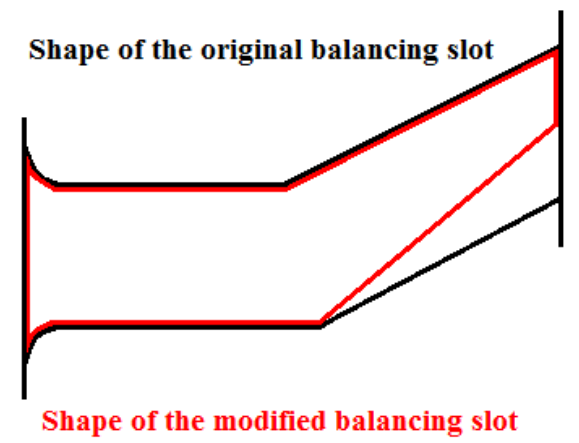

Figure 8. Shapes of the original and modified balancing slots

This shape modification of the balancing slot clearly minimizes the geometric impact of the rotor blade. Gradual narrowing of the balancing slot's inner channel should lead to the change in the outlet angle and to the acceleration of the steam flow at its outlet. The question, whether this modification of the balancing slot's shape will really bring about the increase in its mechanical output and the improvement of corresponding turbine stage efficiency respectively remains.

To answer this question, CFD calculations of two-stage steam turbines with the original as well as modified balancing slots have been carried out. 


\section{Calculation Model}

The calculation model includes 2 complete turbine stages including their shaft seals and tip seals (see figure 9). This complexity of the calculation model will guarantee the exact condition for the steam flow through the balancing slot.

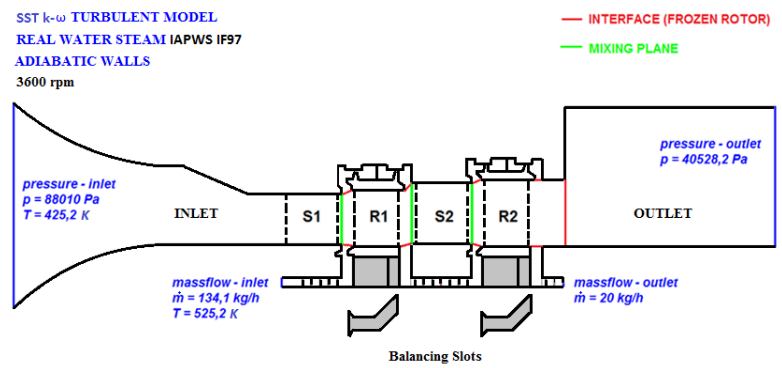

Figure 9. Calculation model

The mesh of the calculation model is prepared either in ANSYS TurboGrid 15.0 (stator and rotor domains) or in ANSYS Meshing 15.0 (shaft and tip seal domains). The mesh of the calculation model including several details in selected places is shown in figure 10 .

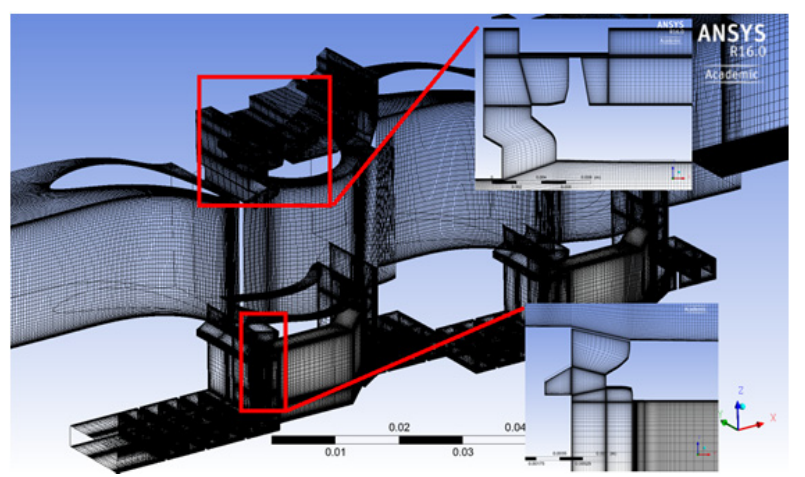

Figure 10. Mesh of the calculation model

The inlet and outlet boundary conditions of the calculation model are set by pressures, temperature and mass flux which were measured in the experiments. All calculations are accomplished in ANSYS CFX 15.0 using database IAPWS IF97 describing the real steam properties.

Two calculation variants (variant0 with the original balancing slots and variantl with modified balancing slots) are carried out and their results are subsequently compared.

\section{Results}

In figure 11 the pressure distribution on the control lines is compared. In this picture it is possible to observe that the profit part of the variantl (variant with modified balancing slots) is larger than that of the variant0 (variant with original balancing slots). This expansion of the profit part in the variantl brought about considerable increase in its mechanical output.
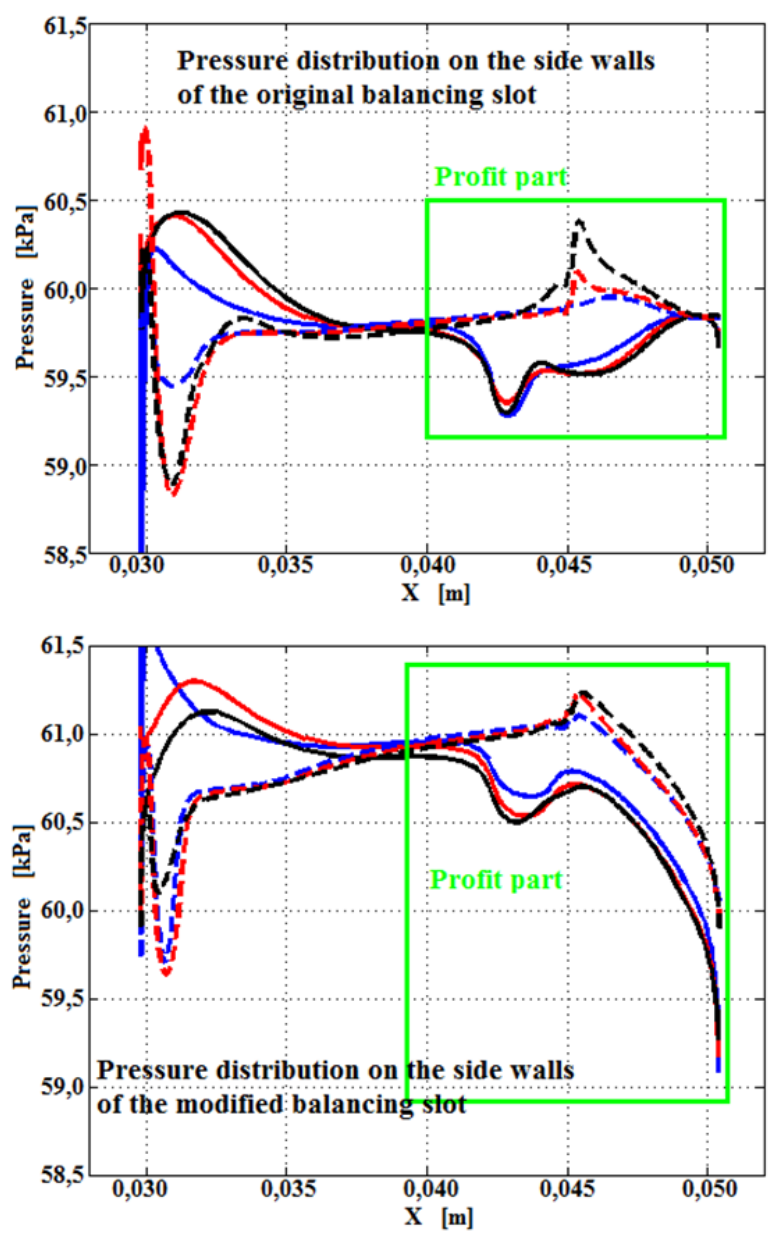

Figure 11. Comparison of the profit part of the balancing slot of variant 0 and variant 1

As is seen in figure 12, mechanical output of the modified balancing slot is about 2 times higher than the output of the original slot.

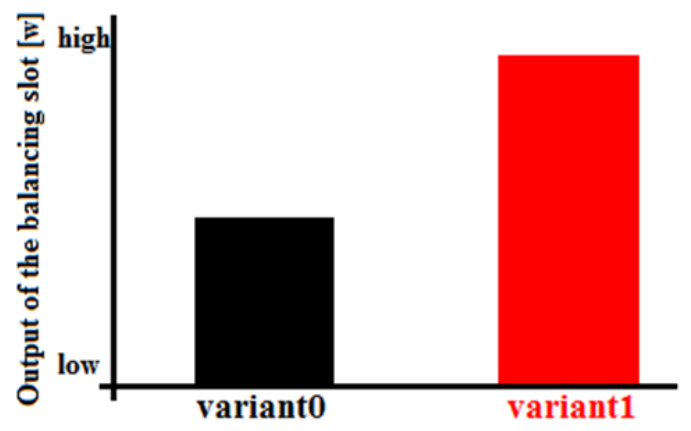

Figure 12. Comparison of the output of the balancing slot of variant 0 and variant 1

This increase in mechanical output of the balancing slot in variant1 contributes to the improvement of its efficiency. Specifically, the efficiency of the variant 1 with the modified balancing slots is $0.52 \%$ higher than the efficiency of the variant 0 with the original balancing slots. 


\section{Conclusion}

After detailed analysis of the steam flow through the balancing slot, it was discovered that the change in the outlet angle and the acceleration of the steam flow at the balancing slot's outlet can cause an increase in its mechanical output. Each shape modification of the balancing slot is related to a geometric change of the rotor blade, which is very demanding concerning both construction and technology. Therefore we had to find the shape modification of the balancing slot, which could be most easily implemented and at the same time enable the change of the outlet angle and acceleration of the steam flow at its outlet.

After consultation with the designers, the new shape of the balancing slot with the narrowing outlet channel was suggested.

Using CFD calculations the benefit of the newly designed balancing slots was verified and its positive influence on the turbine efficiency was confirmed. Replacing the original balancing slots by the modified ones caused improvement in the turbine efficiency by $0.52 \%$.

\section{Acknowledgement}

The authors of the paper would like to thank Czech Technical University in Prague for the financial support within the project with the grant number SGS 14/183.

\section{References}

1. K. Yun, M. Kolovratník, L. Tajč, Proceeding, Experimental Fluid Dynamics 2014, 748-752 (2014)

2. J. Synáč, The steam blowing to the shear layers and their extruding from the side walls of the turbine stage (1992)

3. M. Hoznedl, L. Bednár, L. Tajč, Analysis of the steam flow in the two-stage steam turbine with the drum rotor arrangement, Technical report, Doosan Škoda Power, (2011)

4. K. Yun, Z. Jůza, M. Hoznedl, L. Bednáŕ, L. Tajč, Proceeding, 17th Conference Engineering Mechanics, 671-674, (2011)

5. M. Hoznedl, L. Tajč, Proceeding, 10th European Conference on Turbomachinery, 48-53, (2013) 